\title{
Arterial stiffness in 10-year-old children: current and early determinants
}

\author{
Lene Schack-Nielsen $^{1}$, Christian Mølgaard ${ }^{1}$, Dorthe Larsen ${ }^{1}$, Christopher Martyn ${ }^{2}$ \\ and Kim Fleischer Michaelsen ${ }^{1}$ \\ ${ }^{1}$ Department of Human Nutrition and Centre for Advanced Food Studies, Royal Veterinary and Agricultural University, Rolighedsvej 30, \\ DK-1958 Frederiksberg, Denmark \\ ${ }^{2}$ MRC Environmental Epidemiology Unit, Southampton General Hospital, Southampton, SO16 6YD, UK
}

(Received 5 January 2005 - Revised 14 April 2005 - Accepted 9 May 2005)

\begin{abstract}
It has been suggested that CVD has its origins in early life. An impairment of fetal growth and early postnatal nutrition may have programming effects on cardiovascular physiology. In addition, traditional risk factors for CVD may initiate the atherosclerotic process during childhood. We explored the effect of fat intake, physical activity and lipid profile in childhood, and birth weight, growth during infancy and breast-feeding on arterial stiffness in a cohort study of ninety-three 10-year-old children followed during infancy and re-examined at the age of 10 years. Arterial stiffness in two arterial segments (aorto-radial and aorto-femoral) was measured as pulse wave velocity. Arterial stiffness was inversely associated with physical activity (a regression coefficient in $\mathrm{cm} / \mathrm{s}(95 \%$ $\mathrm{CI})$ of $-6.8(-11.2,-2.4)$ and $-3.9(-6.9,-0.8) \mathrm{per} \mathrm{h}$ of high physical activity/d in the aorto-radial and aorto-femoral segments, respectively). Arterial stiffness was also positively associated with dietary fat energy percentage $(3.1(95 \% \mathrm{CI} 0.9,5 \cdot 2)$ and $1.8(95 \% \mathrm{CI} 0.2,3 \cdot 2)$ per fat energy percentage in the aorto-radial and aorto-femoral segments, respectively) but was not related to body composition, insulin resistance or lipid profile. Arterial stiffness was also positively associated with duration of breast-feeding for the aorto-femoral segment only ( 2.1 (95\% CI $0.4,3.7)$ per month) but was not associated with growth in early life. In conclusion, patterns of physical activity and diet, and history of breast-feeding in infancy, have an influence on the stiffness of the large arteries in children. The long-term effects of this are unknown.
\end{abstract}

Arterial stiffness: Pulse wave velocity: Fat intake: Physical activity: Breast-feeding: Birth weight: Growth: Programming: Lipid profile: Insulin

Most studies have shown that low birth weight is associated with an increased risk of CVD, and it has also become evident that a low weight gain during infancy followed by an accelerated weight gain in childhood further increases the risk of CVD. This is now called the 'developmental origins hypothesis' (Barker 2004). Early nutrition may also have long-term effects on the risk of CVD since breast-feeding is associated with a small reduction in blood pressure (Owen et al. 2003) and serum cholesterol in later life (Owen et al. 2002). Furthermore, pathological studies have shown that the atherosclerotic process starts during childhood (Stary, 2000), and from the late teens associations between the early stages of atherosclerotic lesions and CVD risk factors have been seen (McGill et al. 2000). This suggests that traditional CVD risk factors may be acting several decades before CVD becomes manifest. Additionally, obesity in childhood is associated with insulin resistance, increased blood pressure and a more adverse lipid profile (Lobstein et al. 2004).

Arterial stiffness (AS) is determined by the arterial wall structure and is, in adults, associated with numerous well-established risk factors for CVD (Arnett et al. 1994) and increased in patients with atherosclerotic disease (van Popele et al. 2001). Furthermore, AS has been shown to be a predictor of cardiovascular mortality in certain patient groups (Laurent et al. 2001; Blacher et al. 2003) and in the elderly (Meaume et al. 2001). AS is also affected by the mean arterial blood pressure and smooth muscle tone, which are in turn influenced by the endothelial function, sympathetic neuronal activity and eicosanoides (Mottram et al. 1999). Only a few studies have measured AS in children, showing a positive association between serum cholesterol and AS in a population-based study (Leeson et al. 2000), and increased AS in children with hypercholesterolaemia (Aggoun et al. 2000) and severe obesity (Tounian et al. 2001).

Three types of AS can be considered - systemic, regional and local - describing the overall stiffness of the arterial system, the stiffness in a specific arterial segment and the stiffness at a local site, respectively (Pannier et al. 2002). Regional AS can be measured indirectly by measuring pulse wave velocity (PWV) over the segment of interest and is calculated as the distance in meters divided by the transit time in seconds (Van Bortel et al. 2002). PWV is one of many indices for AS, none of which has proven superior, and all have their weaknesses (O'Rourke et al. 2002). Other often-used indices are compliance and distensibility, which are the absolute or relative change in arterial diameter and pressure at a local point, respectively (O'Rourke et al. 2002). 
PWV is inversely related to the distensibility (D) by the Bramwell-Hill formula:

$$
\mathrm{PWV}=\sqrt{ }(1 / \rho \times \mathrm{D})
$$

where $\rho$ represents blood density (Van Bortel et al. 2002).

The aim of the present study was to explore the effect of the current lifestyle factors of fat intake and physical activity, and the early-life factors of breast-feeding and growth in early life, on AS measured as PWV in 10-year-old healthy Danish children.

\section{Subjects and methods}

\section{Copenhagen Cohort Study on Infant Nutrition and Growth}

The Copenhagen Cohort Study on Infant Nutrition and Growth was an observational study in which a random sample of infants born at Hvidovre Hospital from October 1987 to February 1988 was followed from birth to 12 months of age. Hvidovre Hospital is the main hospital in the municipality of Copenhagen, and the participating families were comparable with those in the remaining area with respect to the number with low income and poor housing. Two hundred and fifty-one infants out of 560 infants born during 109 predetermined days fulfilled the following inclusion criteria: parents of Danish origin, singleton birth, gestational age between 37 and 42 weeks, birth weight for gestational age between the 10th and 90th percentiles, no neonatal diseases resulting in admission to the neonatal department and no severe malformations, and mother and infant admitted to the hospital for at least $3 \mathrm{~d}$.

The infants were randomised to a study group ( $n$ 139) who were examined eight times during infancy, or a control group ( $n$ 112) who were examined only at the age of 9 months. The control group was not contacted until 8 months after delivery. In the study group, ninety-one families agreed to participate, and eightyfour completed the study. In the control group, fifty-nine families agreed to participate. Based on information available from hospital records, participants and non-participants were compared with respect to maternal age, weight, height, BMI and several birth variables, the only difference being that non-participants spent approximately $0.4 \mathrm{~d}$ less on the maternity ward.

To test whether participating in the study group, with the frequent contact with the investigators, influenced dietary pattern and growth, a number of dietary and growth characteristics at 9 months were compared between the study and the control group. No major differences were seen between the groups, implying that participation in the study did not have any significant impact on the nutrition or growth of the infants. A more detailed description has been published elsewhere (Michaelsen, 1997).

\section{Follow-up}

Of the 143 children participating in the original study, 136 were invited to the 10-year follow-up examination (October 1997 to February 1998). Two were not invited because they lived outside Denmark, and no addresses could be found for the remaining five children at the Central Person Registry in Denmark. One hundred and six children (fifty-one boys) agreed to participate. Children participating in the follow-up examination were compared with children not attending the follow-up examination with respect to duration of breast-feeding, size and growth in infancy (weight, length and skin folds at birth and at 9 months of age). No significant differences were seen (data not shown).
Furthermore, maternal social group at birth did not differ between children participating and children not participating in the followup examination.

\section{Ethical considerations}

The study was performed in agreement with the Declaration of Helsinki (1964) and approved by the local ethical committee (Journal no. KF-01-226/97).

\section{Infancy}

Weight at birth was available from medical records, and at 9 months of age the infant was measured naked on an electronic balance to the nearest gram. Crown-heel length was measured on the fourth or fifth day of life and at 9 months of age, with the mother holding the head of the infant, using a wooden measuring board with a fixed headboard and a movable footboard. At 9 months of age, triceps and subscapular skinfolds were measured using the Harpenden skinfold caliper (Chasmors Ltd, London, UK) according to standard procedures (Tanner \& Whitehouse 1975).

Breast-feeding status was reported monthly for the study group but only at the 9-month examination for the control group. Information collected at the 9-month examination on duration of breast-feeding measured in whole months was therefore used for both groups, and 9 months therefore also became the maximum duration even though $34 \%$ of the infants in the study group were still being partially breast-fed at this time. Breast-feeding was defined as exclusive or partial. Exclusive breast-feeding allowed supplements of water or camomile tea with no sugar or milk (commonly used for infants in Denmark). Infants were classified as partially breast-fed as long as they were breast-fed at least once a day. In this study, the total duration of breast-feeding, calculated as the sum of exclusive and partial breast-feeding, was used.

\section{Follow-up examination}

Height was measured to the nearest $1 \mathrm{~mm}$ using a wall-mounted digital stadiometer (FORCE Institute, Copenhagen, Denmark) and weight was measured to the nearest $0 \cdot 1 \mathrm{~kg}$ using an electronic digital scale (Model 707, Seca, COMACO A/S, Hammel, Denmark). Subjects wore only underpants and a cotton T-shirt when weighed. BMI was calculated as $\mathrm{kg} / \mathrm{m}^{2}$. Body fat percentage was determined by dual-energy X-ray absorptiometry using a Hologic 1000/W (Hologic, Waltham, MA, USA). For analysis, software version 5.61 was used. Stages of puberty were assessed using the method of Tanner (1962). Breast development in girls and pubic hair development in boys were used to assess pubertal stage.

Venous blood samples were collected after an overnight fast. Concentrations of total cholesterol and triacylglycerol were measured by an enzymatic assay (Boehringer Mannheim, Mannheim, Germany). HDL-cholesterol was measured by a homogenous method after the specific binding of LDL and VLDL cholesterol by $\alpha$-cyclodextrin (Boehringer Mannheim, Mannheim, Germany). LDL-cholesterol was calculated by the Friedewald formula:

$$
\begin{aligned}
\mathrm{LDL}-\text { cholesterol }= & \text { total cholesterol }-(\mathrm{HDL} \text { cholesterol } \\
& + \text { triacylglycerols } / 2.2)
\end{aligned}
$$

Glucose was measured by the hexokinase method (Boehringer Mannheim) after haemolysis (Merck KgaA, Germany). Insulin 
was measured by a solid phase, two-site fluorometric assay (Wallac Oy, Turku, Finland). The homeostasis model assessment, which has been proposed as a method of assessing insulin resistance from fasting glucose and insulin concentrations, was calculated as (Matthews et al. 1985):

$$
\text { insulin }(\mu \mathrm{U} / \mathrm{ml}) \times \text { glucose }(\mathrm{mmol} / \mathrm{l}) / 22.5
$$

Blood pressure and pulse were measured with an electronic instrument (Omron HEM-705CP; Omron Corporation, Japan). The measurement was performed after $10 \mathrm{~min}$ of rest in the supine position both before and after measuring PWV in the aorto-radial (AR) segment, and after measuring PWV in the aorto-femoral (AF) segment.

The participants (and their parents) kept a $7 \mathrm{~d}$ food record with pre-printed response categories supplemented with open-ended alternatives, using household measures, similar to the methods of the national dietary survey (Andersen et al. 1996). Before parents completed the questionnaire, the description and reporting of serving size and frequency of food intake was explained to them with the aid of food portions and common household measures. After school, the children reported to the parents what foods, snacks and beverages they had eaten at school. The importance of maintaining the habitual dietary intake during the $7 \mathrm{~d}$ period was emphasised to both children and parents. Average daily intakes of energy and fat were calculated for each subject by using the national food database of the Danish Food Agency.

Physical activity was recorded using a Danish version of a $24 \mathrm{~h}$ recall questionnaire (Habitual Activity Estimation Scale; Boucher et al. 1997). The day was divided into four periods: before breakfast, breakfast to lunch, lunch to dinner, and dinner to bedtime. In each of these periods, records were made of the amount of time (\%) spent in activity levels corresponding to the following activities: (I) lying, (II) sitting, (III) walking, (IV) playing or sport that affected breathing. From this, a total time duration in each activity level during the whole day was calculated. In a Danish validation study with children, h/d spent in the highest activity level was strongly associated with data from Caltrac activity monitors (Model C100, Caltrac Activity Monitor, Caltronics Div., Hemokinetics Inc., Vienna, Virginia, USA), which was not the case for the other activity levels (Mølgaard, 1996). The highest activity level was therefore used as an estimate of physical activity level in this study. Physical activity was registered for the day before the examination by filling out the form on the day they were examined; this could therefore have been any day from Sunday to Thursday.

AS was determined as PWV by a non-invasive optical method. It was measured in two arterial segments from the heart to the radial artery at the wrist, and from the heart to the femoral artery at the level of the inguinal ligament. An electrocardiogram belt, with an electrode on each side of the heart, was placed around the chest. The pulse at the wrist or groin was localised and an infrared transducer (MRC Environmental Epidemiology Unit, Southampton University, UK) placed over it. The position of the transducer was adjusted until a clear pulse curve with a sharp increase was found. Pulse and electrocardiogram were measured with the programme Pulse, version 4.0 (MRC Enviromental Epidemiology Unit, Southampton University, UK). The electrocardiogram and pulse curve were then measured over $20 \mathrm{~s}$, and transit time was calculated as time from the R peak in the electrocardiogram to the transducer registered the beginning of the pulse curve. The analysis program used was Pulse Analysis version 97.1.1 (MRC Environmental Epidemiology Unit, Southampton University, UK), which normally automatically calculates the transit time, although in some cases it was necessary to identify the $\mathrm{R}$ peak and the beginning of the pulse curve manually.

The distance between the heart (sternal notch) and the transducer was measured to the nearest $0.5 \mathrm{~cm}$ using a tape measure. PWV was then calculated as the distance travelled divided by the transit time. The method has recently been shown to correlate well with results obtained using Doppler ultrasound and intraarterial measurements (Loukogeorgakis et al. 2002).

\section{Statistical analyses}

Results are expressed as means and standard deviations unless otherwise stated. Differences between boys and girls were determined by two-sided Student's $t$ test or Mann-Whitney test. Determinants of PWV were explored in multiple linear regression analyses. The level of significance was set to 0.05. All analyses were performed with SPSS (version 10; SPSS Inc., Chicago, IL, USA).

To adjust fat intake for total energy intake, the method suggested by Willet \& Stampfer (1998) was used. Briefly, fat intake $(\mathrm{g} / \mathrm{d})$ was regressed on energy intake $(\mathrm{MJ} / \mathrm{d})$. Mean fat intake was then added to the residuals from this model, providing an estimate for fat intake unrelated to total energy intake.

\section{Results}

\section{Basic characteristics at 10 years of age}

Owing to technical problems, PWV was not measured in either of the two arterial segments in five children, only in the AR segment in four children, and only in the AF segment in three children, leaving ninety-three children (forty-four boys) with both measurements. The majority of the children (forty-one boys, thirty-two girls) showed no signs of pubertal development (Tanner stage I), whereas two boys and fifteen girls were in Tanner stage II, and only two girls were in Tanner stage III. Pubertal development was not assessed in one boy.

There were no significant differences between boys and girls in terms of age, height, weight and BMI (Table 1), whereas girls had a significantly higher body fat percentage than boys. According to international BMI cut-offs (Cole et al. 2000), four girls and four boys were overweight, and none was obese. LDL- and HDLcholesterol levels did not differ significantly between boys and girls, but triacylglycerol levels and the homeostasis model assessment index were significantly higher in girls than in boys. Both LDL- and HDL-cholesterol were close to values found in American children (Olson, 2000). Boys had a significantly higher energy intake than girls, whereas the fat energy percentage, fat composition of the diet and physical activity did not show any gender differences. Energy and fat intakes were close to Danish reference values (Andersen et al. 1996).

Results from the measurements of the cardiovascular variables are shown in Table 2; these did not differ significantly between girls and boys except for pulse rate, which was significantly higher in girls than in boys.

\section{Basic characteristics in infancy}

Boys and girls did not differ significantly in size at birth (Table 3), whereas boys were significantly heavier and longer at 9 months of 
Table 1. Basic characteristics at the age of 10 years

\begin{tabular}{|c|c|c|c|c|c|c|}
\hline & \multicolumn{3}{|c|}{ Girls } & \multicolumn{3}{|c|}{ Boys } \\
\hline & $n$ & Mean & SD & $n$ & Mean & SD \\
\hline Age (years) & 49 & 9.97 & 0.08 & 44 & 9.96 & $0 \cdot 10$ \\
\hline Height $(\mathrm{cm})$ & 49 & $141 \cdot 2$ & 5.8 & 44 & $143 \cdot 2$ & $5 \cdot 3$ \\
\hline Weight (kg) & 49 & $34 \cdot 0$ & 4.9 & 44 & $35 \cdot 0$ & 4.9 \\
\hline $\mathrm{BMI}\left(\mathrm{kg} / \mathrm{m}^{2}\right)$ & 49 & $17 \cdot 0$ & $2 \cdot 1$ & 44 & $17 \cdot 0$ & 1.8 \\
\hline Body fat percentage & 49 & $22 \cdot 7$ & $3 \cdot 9$ & 44 & $19 \cdot 0^{* \star *}$ & $4 \cdot 0$ \\
\hline Triacylglycerol (mmol/l) & 48 & 0.75 & 0.34 & 41 & $0.57^{\star \star}$ & 0.21 \\
\hline LDL-cholesterol (mmol/l) & 48 & $2 \cdot 46$ & 0.56 & 42 & $2 \cdot 27$ & 0.48 \\
\hline HDL-cholesterol (mmol/l) & 48 & 1.43 & 0.27 & 42 & 1.44 & 0.25 \\
\hline HOMA (index) & 45 & $1 \cdot 15$ & 0.66 & 37 & $0.85^{\star}$ & 0.33 \\
\hline Energy intake (kJ/d) & 47 & 9078 & 1357 & 42 & 10 & 1702 \\
\hline Dietary fat (energy \%) & 47 & $35 \cdot 2$ & 3.7 & 42 & $35 \cdot 7$ & $4 \cdot 3$ \\
\hline Dietary saturated fat (energy \%) & 47 & $15 \cdot 6$ & $2 \cdot 1$ & 42 & $15 \cdot 7$ & $2 \cdot 1$ \\
\hline Dietary MUFA (energy \%) & 47 & $10 \cdot 1$ & $1 \cdot 2$ & 42 & $10 \cdot 1$ & 1.6 \\
\hline Dietary PUFA (energy \%) & 47 & $4 \cdot 3$ & 0.8 & 42 & 1.3 & 0.7 \\
\hline Physical activity $(\mathrm{h} / \mathrm{d}) \dagger$ & 49 & $3 \cdot 3$ & $2 \cdot 0$ & 43 & $4 \cdot 1$ & 1.8 \\
\hline
\end{tabular}

HOMA, homeostasis model assessment.

${ }^{*} P<0.05,{ }^{*} P<0.01,{ }^{\star \star *} P<0.001$, for girls compared with boys.

† At the highest activity level; for further details see p. 1006.

age. Duration of breast-feeding showed no significant difference between boys and girls.

\section{Correlations between the variables studied}

Correlation coefficients adjusted for gender are shown in Table 4. $\mathrm{PWV}$ in the AR and AF segment was positively correlated $(r=0.57, P<0 \cdot 001)$, and both were positively correlated with systolic blood pressure, and negatively correlated with physical activity. In addition, PWV in the AR segment was positively correlated with diastolic blood pressure, BMI and body fat percentage, whereas $\mathrm{PWV}$ in the AF segment was positively correlated with the duration of breast-feeding.

\section{Determinants of pulse wave velocity}

All models included a constant and were adjusted for gender, height, weight, body fat percentage and blood pressure. Adjusting for blood pressure is necessary since AS is directly related to the blood pressure (London, 1995). In the initial model, the influence of cardiovascular variables, lipid profile and homeostasis model assessment were explored: none was significantly associated with PWV (Table 5). An analysis, including the LDL-:HDL-cholesterol ratio

Table 2. Basic characteristics at the age of 10 years

\begin{tabular}{|c|c|c|c|c|c|c|}
\hline & \multicolumn{3}{|c|}{ Girls } & \multicolumn{3}{|c|}{ Boys } \\
\hline & $n$ & Mean & SD & $n$ & Mean & SD \\
\hline Pulse (beat/min) & 46 & 80 & 10 & 44 & $75^{\star \star}$ & 8 \\
\hline $\begin{array}{l}\text { Systolic blood pressure } \\
\text { (mmHg) }\end{array}$ & 49 & 109 & 7 & 44 & 109 & 8 \\
\hline $\begin{array}{l}\text { Diastolic blood pressure } \\
\qquad(\mathrm{mmHg})\end{array}$ & 49 & 61 & 5 & 44 & 60 & 5 \\
\hline PWV (aorto-radial) (m/s) & 49 & 3.9 & 0.5 & 44 & $3 \cdot 8$ & 0.4 \\
\hline PWV (aorto-femoral) (m/s) & 49 & $2 \cdot 6$ & 0.3 & 44 & $2 \cdot 6$ & 0.2 \\
\hline
\end{tabular}

PWV, pulse wave velocity.

${ }^{* *} P<0.01$ for girls compared with boys (Mann-Whitney test). instead of LDL- and HDL-cholesterol but otherwise the same variables as in Table 5, showed that the cholesterol ratio also had no influence on PWV (data not shown).

In the second model, energy intake, dietary fat intake, physical activity and duration of breast-feeding were included. Fat energy percentage was positively, and physical activity negatively, associated with PWV in both segments, whereas energy intake was only associated with PWV in the AR segment (Table 6). Furthermore, duration of breast-feeding was positively associated with PWV, but significantly only in the AF segment. Including maternal social class at birth in the model did not change any of the estimates (data not shown). Adding fat composition, expressed as the ratio of saturated fatty acid energy percentage to MUFA energy percentage or saturated fatty acid energy percentage to PUFA energy percentage, to the model shown in Table 6 showed that it was not associated with PWV (data not shown). We also tried to include fat intake adjusted for total energy intake. In these models, which were otherwise identical to the models shown in Table 6 and also included total energy intake, fat intake was also positively associated with PWV in the AR segment $(1.4(\mathrm{SD} 0.5) \mathrm{cm} / \mathrm{s}$ per fat energy percentage; $P=0.004)$ and almost significant in the AF segment (0.7 (SD 0.4) $\mathrm{cm} / \mathrm{s}$ per fat energy percentage; $P=0.051$ ).

In the third model, variables relating to infancy were added. Size at birth (weight, height, ponderal index) and size at 9 months of age (weight, height, ponderal index) were added singly or in combination, for example weight at birth and weight at 9 months of age, thus also testing the influence of growth during the first 9 months (Cole et al. 2001). None of the anthropometric measurements was significantly associated with PWV in any of the arterial segments (data not shown).

Gender, weight, height and body fat were not significantly associated with PWV in any of the multivariate analyses.

\section{Discussion}

In this study of 10-year-old children, we found that the stiffness of two arterial segments was increased in children with low levels of physical activity and with high dietary fat intakes. Stiffness of the 
Table 3. Basic characteristics in infancy

\begin{tabular}{|c|c|c|c|c|c|c|}
\hline & \multicolumn{3}{|c|}{ Girls } & \multicolumn{3}{|c|}{ Boys } \\
\hline & $n$ & Mean & SD & $n$ & Mean & SD \\
\hline Birth weight (g) & 49 & 3424 & 300 & 44 & 3534 & 406 \\
\hline Birth length $(\mathrm{cm})$ & 49 & $52 \cdot 0$ & $1 \cdot 8$ & 44 & $52 \cdot 2$ & $2 \cdot 0$ \\
\hline Ponderal index at birth $\left(\mathrm{kg} / \mathrm{m}^{3}\right)$ & 49 & $24 \cdot 4$ & $2 \cdot 1$ & 44 & $24 \cdot 8$ & $2 \cdot 2$ \\
\hline Weight at 9 months $(\mathrm{g})$ & 49 & 8582 & 884 & 42 & $9489^{\star \star *}$ & 1001 \\
\hline Length at 9 months $(\mathrm{cm})$ & 49 & $70 \cdot 6$ & $2 \cdot 2$ & 42 & $72 \cdot 8^{\star \star \star}$ & $2 \cdot 3$ \\
\hline Ponderal index at 9 months $\left(\mathrm{kg} / \mathrm{m}^{3}\right)$ & 49 & $24 \cdot 4$ & $2 \cdot 1$ & 42 & $24 \cdot 6$ & $2 \cdot 2$ \\
\hline Breast-feeding (months) $\dagger$ & 48 & 6.5 & $(0-9)$ & 44 & 5.5 & $(0-9)$ \\
\hline
\end{tabular}

*** $P<0.001$.

†Data are median (range) owing to a deviation from normal distribution.

Table 4. Correlations adjusted for gender $(n)$

\begin{tabular}{lrr}
\hline & PWV (aorto-radial) & PWV (aorto-femoral) \\
\hline Systolic blood pressure & $0.33^{\star \star *}(93)$ & $0.27^{\star *}(93)$ \\
Diastolic blood pressure & $0.37^{\star \star *}(93)$ & $0.18(93)$ \\
Pulse & $0.13(90)$ & $0.16(90)$ \\
Height & $0.02(93)$ & $0.16(93)$ \\
Weight & $0.18(93)$ & $0.10(93)$ \\
BMl & $0.21^{*}(93)$ & $-0.01(93)$ \\
Body fat \% & $0.23^{\star}(93)$ & $-0.02(93)$ \\
LDL-cholesterol & $0.20(90)$ & $0.08(90)$ \\
HDL-cholesterol & $-0.06(90)$ & $-0.07(90)$ \\
Triacylglycerol & $0.13(89)$ & $0.05(89)$ \\
HOMA & $0.11(82)$ & $0.13(82)$ \\
Physical activity & $0.26^{*}(92)$ & $-0.26^{*}(92)$ \\
Diet fat energy percentage & $0.12(89)$ & $0.11(86)$ \\
Birth weight & $0.04(93)$ & $0.09(93)$ \\
Breast-feeding & $0.10(92)$ & $0.23^{*}(92)$ \\
\hline
\end{tabular}

PWV, pulse wave velocity; HOMA, homeostasis model assessment.

${ }^{\star} P<0.05,{ }^{\star \star} P<0.01,{ }^{\star \star \star} P<0.001$ (Significance of the individual $\beta$-coefficients).

AF arterial segment, but not the AR segment, was greater in those who had been breast-fed for longer. Together, these factors explained $32 \%$ and $20 \%$ of the variation in AS in the AR and AF segments, respectively.

The strengths of the study population are that it is a wellcharacterised random sample of healthy Danish children followed up at the same age, and that the information on breast-feeding was collected in infancy. The prevalence of overweight was $9 \%$ in our study, not very different from the $13 \%$ found among schoolchildren examined during the same years (Pearson et al. 2005). Overweight children might be more reluctant to participate in the follow-up, which could explain the difference. However, we did not find that this was an important limitation as we were studying biological phenomena within the group. PWV is an accepted and useful index of AS, which can be measured both accurately and reproducibly (Lehmann, 2000) and is found to correlate well with intra-arterial measurements (Loukogeorgakis et al. 2002). A weakness of the method is that the long-term consequences of increased AS in childhood are not known, but studies of certain adult patient groups (Laurent et al. 2001; Blacher et al. 2003) and the elderly (Meaume et al. 2001) suggest that AS is associated with an increased risk of CVD.

The adverse effect of a high fat intake on AS in childhood seen in our study has not been reported before but is in agreement with an intervention study in obese adults showing an improvement in AS after 4 weeks with a low fat intake (Nestel et al. 1997). This fast change in AS suggests that structural changes in the vessel wall could not be the mechanism. Furthermore, a fatty meal has an acute effect on endothelial function (Vogel et al. 1997; Gokce et al. 2001), which could be mediated by a systemic change in basal arterial tone (Gokce et al. 2001) that will also affect AS. However, the mechanisms explaining an association between daily fat intake and the acute effect of a fatty meal on AS could be different. Fat composition was not associated with AS in the present study, whereas a high PUFA intake in an intervention studies of obese adults was associated with an improved

Table 5. Pulse wave velocity (PWV) and lipid profile (Results from a multiple linear regression with PWV as the dependent variable and all the variables in the table included in the same model $\dagger$ )

\begin{tabular}{|c|c|c|c|c|c|c|}
\hline & \multicolumn{3}{|c|}{$\begin{array}{l}\text { PWV (aorto-radial) in cm/s } \\
\left(n 79, \text { adjusted } R^{2}=0.03 \text { ) }\right.\end{array}$} & \multicolumn{3}{|c|}{$\begin{array}{l}\text { PWV (aorto-femoral) in } \mathrm{cm} / \mathrm{s} \\
\left(n 79, \text { adjusted } R^{2}=-0.05\right)\end{array}$} \\
\hline & $\beta$ & $95 \% \mathrm{Cl}$ & Partial $r$ & $\beta$ & $95 \% \mathrm{Cl}$ & Partial $r$ \\
\hline Body fat $(\%)$ & $2 \cdot 4$ & $-1 \cdot 5,6 \cdot 3$ & 0.15 & 0.6 & $-1 \cdot 8,2 \cdot 9$ & 0.06 \\
\hline Pulse (beat/min) & -0.7 & $-1 \cdot 8,0.5$ & -0.14 & -0.2 & $-0.9,0.5$ & -0.07 \\
\hline Systolic blood pressure $(\mathrm{mm} \mathrm{Hg})$ & $1 \cdot 3$ & $-0.4,2.9$ & 0.19 & 0.9 & $-0.1,1.9$ & $0 \cdot 21$ \\
\hline Diastolic blood pressure $(\mathrm{mm} \mathrm{Hg})$ & $1 \cdot 3$ & $-1 \cdot 8,4 \cdot 3$ & $0 \cdot 10$ & -0.8 & $-2 \cdot 6,1 \cdot 1$ & $-0 \cdot 10$ \\
\hline Triacylglycerol $(\mathrm{mmol} / \mathrm{l})$ & $14 \cdot 5$ & $-23 \cdot 0,51 \cdot 9$ & 0.09 & $-3 \cdot 3$ & $-26 \cdot 3,19 \cdot 7$ & -0.04 \\
\hline HDL-cholesterol $(\mathrm{mmol} / \mathrm{l})$ & 0.8 & $-40 \cdot 2,41 \cdot 8$ & 0.01 & -0.3 & $-25 \cdot 5,24 \cdot 9$ & 0.00 \\
\hline LDL-cholesterol (mmol/l) & $6 \cdot 1$ & $-13 \cdot 4,25 \cdot 6$ & 0.08 & 2.5 & $-9.5,14.5$ & 0.05 \\
\hline HOMA (index) & $-5 \cdot 3$ & $-27 \cdot 0,16 \cdot 4$ & -0.06 & $6 \cdot 7$ & $-6 \cdot 6,20 \cdot 1$ & 0.12 \\
\hline
\end{tabular}

HOMA, homeostasis model assessment.

† Adjusted for gender, height and weight. 
Table 6. Pulse wave velocity (PWV), fat intake, physical activity and breast-feeding (Results from a multiple linear regression with PWV as the dependent variable and all the variables in the table included in the same model + )

\begin{tabular}{|c|c|c|c|c|c|c|}
\hline & \multicolumn{3}{|c|}{$\begin{array}{l}\text { PWV (aorto-radial) in } \mathrm{cm} / \mathrm{s} \\
\text { ( } n 87, \text { adjusted } R^{2}=0.32 \text { ) }\end{array}$} & \multicolumn{3}{|c|}{$\begin{array}{l}\text { PWV (aorto-femoral) in cm/s } \\
\left(n 87, \text { adjusted } R^{2}=0.20\right)\end{array}$} \\
\hline & $\beta$ & $95 \% \mathrm{Cl}$ & Partial $r$ & $\beta$ & $95 \% \mathrm{Cl}$ & Partial $r$ \\
\hline Body fat $(\%)$ & 1.4 & $-1.9,4.6$ & 0.09 & $-1 \cdot 7$ & $-3.9,0.5$ & -0.17 \\
\hline Systolic blood pressure $(\mathrm{mm} \mathrm{Hg})$ & $1 \cdot 2$ & $-0 \cdot 1,2 \cdot 5$ & 0.21 & 0.7 & $-0.2,1.6$ & 0.17 \\
\hline Diastolic blood pressure $(\mathrm{mm} \mathrm{Hg})$ & $2 \cdot 4$ & $-0.1,4 \cdot 8$ & 0.22 & $1 \cdot 2$ & $-0.4,2.9$ & 0.17 \\
\hline Energy $(\mathrm{MJ} / \mathrm{d})$ & $-6 \cdot 4^{\star}$ & $-11 \cdot 7,-0.8$ & -0.25 & $-1 \cdot 8$ & $-5 \cdot 6,2 \cdot 0$ & -0.11 \\
\hline Fat energy percentage (\%) & $3 \cdot 1^{\star \star}$ & $0.9,5 \cdot 2$ & 0.31 & $1 \cdot 8^{*}$ & $0 \cdot 2,3 \cdot 2$ & 0.27 \\
\hline Physical activity $(\mathrm{h} / \mathrm{d})$ & $-6 \cdot 8^{\star \star}$ & $-11 \cdot 2,-2 \cdot 4$ & -0.34 & $-3 \cdot 9^{*}$ & $-6.9,-0.8$ & -0.28 \\
\hline Breast-feeding (months) & 1.6 & $-0.8,4.0$ & 0.15 & $2 \cdot 1^{*}$ & $0.4,3 \cdot 7$ & 0.27 \\
\hline
\end{tabular}

${ }^{\star} P<0.05,{ }^{* \star} P<0.01$ (Significance of the individual $\beta$-coefficients).

† Adjusted for gender, height and weight.

AS (McVeigh et al. 1994; Nestel et al. 1997). It may be that the effect of PUFA on AS is only seen at levels of intake higher than those in our study, where there was also a low variation in intake.

In all analyses, physical activity, measured as $\mathrm{h} / \mathrm{d}$ at the highest activity level, was inversely associated with PWV. Since physical activity was based on only $1 \mathrm{~d}$ of registration, we were surprised to see so consistent an association, which might even be an underestimation of the true association seen if a more detailed registration of physical activity were performed. As far as we know, this has not been explored in children before, but both observational (Kupari et al. 1994; Kakiyama et al. 1998; Tanaka et al. 1998, 2000) and intervention studies of adults support the association (Cameron \& Dart 1994; Tanaka et al. 2000). Animal studies have shown that extended physical exercise increased the elastin content and decreased the calcium content in the aorta (Matsuda et al. 1993), but since an immediate and momentary effect of physical activity on AS was seen after 30 min of physical exercise (Kingwell et al. 1997), other mechanisms must also be involved. Furthermore, a period of physical training of only one arm caused restored flow-dependent vasodilatation in patients with chronic heart failure, but only in the exercised arm, indicating a local mechanism that could be an enhanced release of NO (Hornig et al. 1996). However, different mechanisms could be responsible for the effect of aerobic training and training of specific muscle groups on AS.

In some of our analyses, energy intake was inversely associated with PWV, which is difficult to explain. An explanation could be residual confounding owing to children with a high energy intake also having a high physical activity level, which might not be completely adjusted because of the simple way in which it was measured.

In our regression analysis, there were no significant effects of body size, blood lipids and homeostasis model assessment index. Increased AS has been found in severely obese children (thirty-four) and in children with hypercholesterolaemia, but only few children in our study were overweight and none had hypercholesterolaemia. However, associations between total and LDL-cholesterol and AS have been seen in a population-based study of 9-11-year-old children (Leeson et al. 2000), although this disagreement with our result may be due to a slightly higher mean level of LDL-cholesterol in that study.

A proposed mechanism behind the developmental hypothesis is that fetal growth restriction leads to a reduced elastin content in the vessel walls, resulting in increased AS (Martyn \& Greenwald,
1997). Studies of the association between birth weight and AS have, however, been inconsistent (te Velde et al. 2004), and our study of children with normal birth weight and born at term did not suggest an effect of birth weight or early growth on AS. Cheung et al. (2004) have recently shown that children born preterm and small for gestational age had increased arterial stiffness compared with children born preterm and at term with normal weight for gestational age.

The finding in the AF segment that a longer duration of breastfeeding was associated with increased AS supports an earlier study (Leeson et al. 2001). A possible mechanism is that exposure of the vessel wall to the high level of serum cholesterol during infancy in breast-fed compared with formula-fed infants results in the early formation of arterial fatty streaks (Leeson et al. 2001). That would imply a higher risk of CVD in breast-fed infants. This is, however, not supported by a current meta-analysis (Martin et al. 2004), and, in addition, other meta-analyses suggest that a longer duration of breast-feeding is associated with lower serum cholesterol (Owen et al. 2002) and a small reduction in blood pressure (Owen et al. 2003) in adulthood. Furthermore, studies of children suggest that breast-feeding is associated with a decreased risk of obesity (Arenz et al. 2004), but it is not known whether this association persists into adulthood.

In our study, the association between breast-feeding and AS was significant only in the AF segment, but the association in the AR segment was in the same direction. The difference could also be due to different susceptibilities in the two arteries. The brachial artery is a muscular artery whose compliance would be altered by smooth muscle activity, whereas the central artery from the heart to the groin is a more elastic artery whose stiffness is dependent largely on its scleroprotein content. However, for the other explored variables associated with PWV, i.e. fat intake and physical activity, no differences were seen between the arteries, and the PWV measured in the two arteries were significantly correlated.

Our finding that a low fat intake and a high physical activity might have a beneficial effect on the arterial wall in this sample of healthy 10 -year-old children is in line with the general concept of lifestyle factors that will prevent CVD. The study is, however, based on a small number of children, and our findings should be confirmed in other studies. However, even though there is no firm evidence on the long-term effects of AS values measured in childhood, we believe that the present data support the importance of a healthy lifestyle during childhood, with a low fat intake and high 
physical activity. Additionally, our study tends to support a previous study of an adverse effect of breast-feeding on AS, but since the literature suggests that breast-feeding has beneficial effects on blood pressure, lipid profile and risk of obesity, the present findings should not be used to advise against breast-feeding. In addition to possible positive effects on other risk factors of CVD, breast-feeding has many important beneficial effects, including protection against infectious diseases, long-term effects on the occurrence of certain non-communicable diseases and, most likely, a positive effect on cognitive function reaching into adulthood (Mortensen et al. 2002).

\section{Acknowledgements}

We are grateful to P. Larsen for valuable assistance in collecting data in 1987-8 and to M. Ege for performing most of the practical work, including the $7 \mathrm{~d}$ food record in 1997-8. We thank the Danish Heart Association for financial support.

\section{References}

Aggoun Y, Bonnet D, Sidi D, Girardet JP, Brucker E, Polak M, Safar ME \& Levy BI (2000) Arterial mechanical changes in children with familial hypercholesterolemia. Arterioscler Thromb Vasc Biol 20, 2070-2075.

Andersen NL, Fagt S, Groth MV, Hartkopp HB, Møller A, Ovesen L \& Warming DL (1996) Dietary Habits in Denmark 1995. Main Results. Publication no. 235. Søborg: National Food Agency, [In Danish with an English summary.].

Arenz S, Ruckerl R, Koletzko B \& von Kries R (2004) Breast-feeding and childhood obesity - a systematic review. Int $\mathrm{J}$ Obes Relat Metab Disord 28, (10): 1247-1256.

Arnett DK, Evans GW \& Riley WA (1994) Arterial stiffness: a new cardiovascular risk factor? Am J Epidemiol 140, 669-682.

Barker DJ (2004) Developmental origins of adult health and disease. $J$ Epidemiol Community Health 58, 114-115.

Blacher J, Safar ME, Guerin AP, Pannier B, Marchais SJ \& London GM (2003) Aortic pulse wave velocity index and mortality in end-stage renal disease. Kidney Int 63, 1852-1860.

Boucher GP, Lands LC, Hay JA \& Hornby L (1997) Activity levels and the relationship to lung function and nutritional status in children with cystic fibrosis. Am J Phys Med Rehabil 76, 311-315.

Cameron JD \& Dart AM (1994) Exercise training increases total systemic arterial compliance in humans. Am J Physiol 266, H693-H701.

Cheung YF, Wong KY, Lam BC \& Tsoi NS (2004) Relation of arterial stiffness with gestational age and birth weight. Arch Dis Child 89, 217-221.

Cole TJ, Bellizzi MC, Flegal KM \& Dietz WH (2000) Establishing a standard definition for child overweight and obesity worldwide: international survey. BMJ 320, 1240-1243.

Cole TJ, Fewtrell M \& Lucas A (2001) Early growth and coronary heart disease in later life. Analysis was flawed. BMJ 323, 572-573.

Gokce N, Duffy SJ, Hunter LM, Keaney JF \& Vita JA (2001) Acute hypertriglyceridemia is associated with peripheral vasodilation and increased basal flow in healthy young adults. Am J Cardiol 88, $153-159$.

Hornig B, Maier V \& Drexler H (1996) Physical training improves endothelial function in patients with chronic heart failure. Circulation 93, $210-214$.

Kakiyama T, Matsuda M \& Koseki S (1998) Effect of physical activity on the distensibility of the aortic wall in healthy males. Angiology 49, $749-757$.

Kingwell BA, Berry KL, Cameron JD, Jennings GL \& Dart AM (1997) Arterial compliance increases after moderate-intensity cycling. Am $J$ Physiol 273, H2186-H2191.
Kupari M, Hekali P, Keto P, Poutanen VP, Tikkanen MJ \& Standerstkjold-Nordenstam (1994) Relation of aortic stiffness to factors modifying the risk of atherosclerosis in healthy people. Arterioscler Thromb 14, 386-394.

Laurent S, Boutouyrie P, Asmar R, Gautier I, Laloux B, Guize L, Ducimetiere P \& Benetos A (2001) Aortic stiffness is an independent predictor of all-cause and cardiovascular mortality in hypertensive patients. Hypertension 37, $1236-1241$.

Leeson CP, Kattenhorn M, Deanfield JE \& Lucas A (2001) Duration of breast feeding and arterial distensibility in early adult life: population based study. BMJ 322, 643-647.

Leeson CP, Whincup PH, Cook DG, Mullen MJ, Donald AE, Seymour C \& Deanfield JE (2000) Cholesterol and arterial distensibility in the first decade of life: a population-based study. Circulation 101, $1533-1538$.

Lehmann ED (2000) Aortic pulse-wave velocity versus pulse pressure and pulse-wave analysis. Lancet $\mathbf{3 5 5}, 412$.

Lobstein T, Baur L \& Uauy R (2004) Obesity in children and young people: a crisis in public health. Obes Rev 5, Suppl. 1, 4-85.

London GM (1995) Large artery function and alterations in hypertension. J Hypertens Suppl 13, S35-S38.

Loukogeorgakis S, Dawson R, Phillips N, Martyn CN \& Greenwald SE (2002) Validation of a device to measure arterial pulse wave velocity by a photoplethysmographic method. Physiol Meas 23, 581-596.

McGill HC Jr, McMahan CA, Zieske AW, Sloop GD, Walcott JV, Troxclair DA, Malcolm GT, Tracy RE, Oalmann MC \& Strong JP (2000) Associations of coronary heart disease risk factors with the intermediate lesion of atherosclerosis in youth. The Pathobiological Determinants of Atherosclerosis in Youth (PDAY) Research Group. Arterioscler Thromb Vasc Biol 20, 1998-2004.

McVeigh GE, Brennan GM, Cohn JN, Finkelstein SM, Hayes RJ \& Johnston GD (1994) Fish oil improves arterial compliance in noninsulin-dependent diabetes mellitus. Arterioscler Thromb 14, $1425-1429$.

Martin RM, Davey SG, Mangtani P, Tilling K, Frankel S \& Gunnell D (2004) Breastfeeding and cardiovascular mortality: the Boyd Orr cohort and a systematic review with meta-analysis. Eur Heart J 25, 778-786.

Martyn CN \& Greenwald SE (1997) Impaired synthesis of elastin in walls of aorta and large conduit arteries during early development as an initiating event in pathogenesis of systemic hypertension. Lancet 350, 953-955.

Matsuda M, Nosaka T, Sato M \& Ohshima N (1993) Effects of physical exercise on the elasticity and elastic components of the rat aorta. Eur $J$ Appl Physiol Occup Physiol 66, 122-126.

Matthews DR, Hosker JP, Rudenski AS, Naylor BA, Treacher DF \& Turner RC (1985) Homeostasis model assessment: insulin resistance and betacell function from fasting plasma glucose and insulin concentrations in man. Diabetologia 28, 412-419.

Meaume S, Benetos A, Henry OF, Rudnichi A \& Safar ME (2001) Aortic pulse wave velocity predicts cardiovascular mortality in subjects $>70$ years of age. Arterioscler Thromb Vasc Biol 21, 2046-2050.

Michaelsen KF (1997) Nutrition and growth during infancy. The Copenhagen Cohort Study. Acta Paediatr Suppl 420, 1-36.

Mølgaard C (1996) Bone Mineralization During Puberty. Frederiksberg, Denmark: Department of Human Nutrition, Royal Veterinary and Agricultural University, [In Danish with an English summary.].

Mortensen EL, Michaelsen KF, Sanders SA \& Reinisch JM (2002) The association between duration of breastfeeding and adult intelligence. JAMA 287, 2365-2371.

Mottram P, Shige H \& Nestel P (1999) Vitamin E improves arterial compliance in middle-aged men and women. Atherosclerosis 145, 399-404.

Nestel PJ, Pomeroy SE, Sasahara T, Yamashita T, Liang YL, Dart AM, Jennings GL, Abbey M \& Cameron JD (1997) Arterial compliance in obese subjects is improved with dietary plant $n-3$ fatty acid from flaxseed oil despite increased LDL oxidizability. Arterioscler Thromb Vasc Biol 17, 1163-1170.

Olson RE (2000) Atherogenesis in children: implications for the prevention of atherosclerosis. Adv Pediatr 47, 55-78. 
O'Rourke MF, Staessen JA, Vlachopoulos C, Duprez D \& Plante GE (2002) Clinical applications of arterial stiffness; definitions and reference values. Am J Hypertens 15, 426-444.

Owen CG, Whincup PH, Gilg JA \& Cook DG (2003) Effect of breast feeding in infancy on blood pressure in later life: systematic review and meta-analysis. BMJ 327, 1189-1195.

Owen CG, Whincup PH, Odoki K, Gilg JA \& Cook DG (2002) Infant feeding and blood cholesterol: a study in adolescents and a systematic review. Pediatrics 110, 597-608.

Pannier BM, Avolio AP, Hoeks A, Mancia G \& Takazawa K (2002) Methods and devices for measuring arterial compliance in humans. Am J Hypertens 15, 743-753.

Pearson S, Olsen LW, Hansen B \& Sørensen TIA (2005) Increase in overweight and obesity amongst Copenhagen schoolchildren, 1947-2003. Ugeskr Laeger 167, 158-162.

Stary HC (2000) Lipid and macrophage accumulations in arteries of children and the development of atherosclerosis. Am J Clin Nutr $\mathbf{7 2}$ 1297S-1306S.

Tanaka H, DeSouza CA \& Seals DR (1998) Absence of age-related increase in central arterial stiffness in physically active women. Arterioscler Thromb Vasc Biol 18, 127-132.

Tanaka H, Dinenno FA, Monahan KD, Clevenger CM, DeSouza CA \& Seals DR (2000) Aging, habitual exercise, and dynamic arterial compliance. Circulation 102, 1270-1275.

Tanner JM (1962) Growth of Adolescents. Oxford: Blackwell Scientific.
Tanner JM \& Whitehouse RH (1975) Revised standards for triceps and subscapular skinfolds in British children. Arch Dis Child 50, $142-145$.

te Velde SJ, Ferreira I, Twisk JW, Stehouwer CD, van Mechelen W \& Kemper HC (2004) Birthweight and arterial stiffness and blood pressure in adulthood - results from the Amsterdam Growth and Health Longitudinal Study. Int J Epidemiol 33, 154-161.

Tounian P, Aggoun Y, Dubern B, Varille V, Guy-Grand B, Sidi D, Girardet JP \& Bonnet D (2001) Presence of increased stiffness of the common carotid artery and endothelial dysfunction in severely obese children: a prospective study. Lancet 358, 1400-1404.

Van Bortel LM, Duprez D, Starmans-Kool ME, Safar ME, Giannattasio C, Cockcroft J, Kaiser DR \& Thuillez C (2002) Clinical applications of arterial stiffness, Task Force III: recommendations for user procedures. Am J Hypertens 15, 445-452.

van Popele NM, Grobbee DE, Bots ML, et al. (2001) Association between arterial stiffness and atherosclerosis: the Rotterdam Study. Stroke 32, 454-460.

Vogel RA, Corretti MC \& Plotnick GD (1997) Effect of a single high-fat meal on endothelial function in healthy subjects. Am J Cardiol 79, $350-354$.

Willett W \& Stampfer M (1998) Implications of total energy intake for epidemiologic analyses. In Nutritional Epidemiology, pp. 273-320 [JL Kelsey, MG Marmot, PD Stolley and MP Vessey, editors]. New York: Oxford University Press. 